\title{
Economic growth vs. eco-efficiency of Russian industrial regions
}

\author{
Daria Benz $^{1, *}$ \\ ${ }^{1}$ Chelyabinsk State University, 129, Kashirinykh Br. Str., Chelyabinsk, Russia
}

\begin{abstract}
The article focuses on issues of economic growth, and ecoefficiency in Russian industrial regions on the example of the Urals Federal District. The study is based on the concept of existing tensions between economic development, and eco-efficiency. The author claims that within this concept an optimum could be found. The purpose of the study is to determine the most optimal industrial growth rate within the Urals Federal District. Industrial production representing $50 \%$ of the sectoral gross value added structure is the key factor of economic growth in the researched regions. This basic hypothesis of the study is confirmed by a relatively strong correlation between industrial growth rate and Gross Regional Product growth rate in Sverdlovsk region, Tyumen region, and Chelyabinsk region. As part of the study the author made use of correlation analysis, which confirmed the basic hypothesis of the research, and paired regression analysis, where industrial production growth rate is used as a regressor to build paired regression models. Economic growth is estimated via Gross Regional Product growth rate. For every sector, where the basic hypothesis is confirmed, there is a graphical model illustrating dependence of economic growth $\left(E_{1}\right)$, and eco-efficiency $\left(E_{2}\right)$ on industrial growth rate. The study discovers optimal industrial growth rate providing development of eco-efficiency in the researched regions. The results of the study can be applied both by scientists or government structures in strategies of regional development taking into account eco-efficiency.
\end{abstract}

\section{Introduction}

Economic slowdown is one of the biggest challenges modern world has to face. Russian economy, where decline in economic growth is more frequently considered as routine, is not the exception. The study covers economies of the Urals region.

In current figures the Urals region is $10.62 \%$ of Russian land area, $8.41 \%$ of population, $8.86 \%$ of employed and self-employed people, $13.51 \%$ of Gross Regional Product, and $35.43 \%$ of tax revenue to State budget. The Urals is historically industrial region. $55.5 \%$ of gross value added structure is represented by industrial production up to the end of 2017 . Industrial sector tends to decline in recent years, which is common as to the Urals region (56.7\% in 2005), as for the regions within the Urals Federal District. Only Kurgan region demonstrates growth $(23.6 \%$ in $2005,30.4 \%$ in 2017$)$.

*Corresponding author: benz@csu.ru 
Khanty-Mansiysk Autonomous Region is a leading industrial region, while Kurgan region is the least industrially developed region. The biggest share of manufacturing activity in economy is represented by Chelyabinsk region. However, heterogeneity, observed among the regions of the Urals, is often determined not only by industrial or nonindustrial factors. In comparison with "average" Russian regions, the Urals region demonstrates quite impressive numbers. For instance, $13.51 \%$ of Gross Regional Product, more than one third of mineral output, $18.47 \%$ of fixed assets value, $17.98 \%$ of fixed capital investment. Nevertheless, more detailed analysis shows that these high rates are mostly provided by Tyumen region and its autonomous regions, especially KhantyMansiysk Autonomous Region (KMAR), and Yamalo-Nenets Autonomous Region (YNAR). The latter two regions provide $31.98 \%$ of total tax revenue to State budget, that's why they are often called "tax Atlantes" of Russia.

Kurgan region is a clear example of economic heterogeneity in the Urals region with $0.1 \%$ of tax revenue to State budget, while the Urals Federal District provides $35.43 \%$ of tax revenue. Being mostly agricultural, the economy of Kurgan region still lags behind many other regions by a row of indicators. For example, Chelyabinsk region is an industrial area and only $24 \%$ bigger, but its agricultural output exceeds by 3.3 times the same indicator in Kurgan region, besides, population of Chelyabinsk region is 4.1 times higher.

At the same time a number of certain indicators show that Chelyabinsk region is neither the engine of economic growth. For instance, average per capita income in Chelyabinsk region is $26 \%$ below than the average for the Russian Federation, average monthly wage is $18 \%$ lower than average Russian level. However, in Sverdlovsk region average monthly wage is also below than average for Russia (11\%), while the share of manufacturing activity is higher than in Tyumen region, KMAR, and YNAR.

The purpose of the study is to determine the most optimal level of industrial production for every region of the Urals. The research involves Kurgan region, Svedlovsk region, Tyumen region, and Chelyabinsk region. Optimal level mustn't contradict eco-efficiency.

Main tasks of the research: 1) establish a link between economic growth and industrial production, between industrial production growth and emissions of pollutants into the atmosphere; 2) plot linear regressions (two models for each region). First model shows dependence of economic growth on industrial production growth rate, second model displays dependence of eco-efficiency on industrial production growth rate; 3) define optimal level of industrial production growth rate for each region, and build graphic models displaying optimal values.

\section{Materials and Methods}

Author's concept of eco-economic efficiency is based on the following premises:

1) Economic growth contradicts eco-efficiency.

2) Economic growth is expressed in growth rate of nominal Gross Regional Product (GRP).

3) Eco-efficiency is defined as an inverse value of pollutant emissions into the atmosphere growth rate.

4) The model takes into account only stationary source emissions.

5) Industrial production growth rate remains the key factor determining economic growth, and eco-efficiency (The idea is not a hypothesis, it was confirmed via correlation analysis, and regression analysis [28]. Correlation and dependence for industrial regions was confirmed).

Now let's assume economic growth $\left(E_{l}\right)$ is a function of multiple factors:

$$
E_{1}=f\left(X_{i}\right)
$$


where

$E_{1}$ - economic growth, namely GRP growth rate,

$X_{i}$ - economic growth factors.

Eco-efficiency can also be presented as a function of several factors.

$$
E_{2}=f\left(X_{j}\right)
$$

where

$E_{2}$ - eco-efficiency rate,

$X_{j}$ - eco-efficiency factors.

Eco-efficiency is defined by the author as an inverse value of pollutant stationary source emissions growth rate:

$$
E_{2}=\frac{1}{\text { Pollutant emissions into the atmosphere growth rate }}
$$

Previous work of the author contains the research based on this concept, where function (1) and function (2) are built within multiple regression analysis for the Urals region [28]. The following conclusion was reached : industrial production rate $(i)$ has high elasticity in regard of economic growth $\left(E_{1}\right)$, and eco-efficiency $\left(E_{2}\right)$. In this connection, current research is conducted with focus on single-factor concept, when economic growth and ecoefficiency are single-factor linear functions.

Graphic model of eco-economic efficiency is as follows:

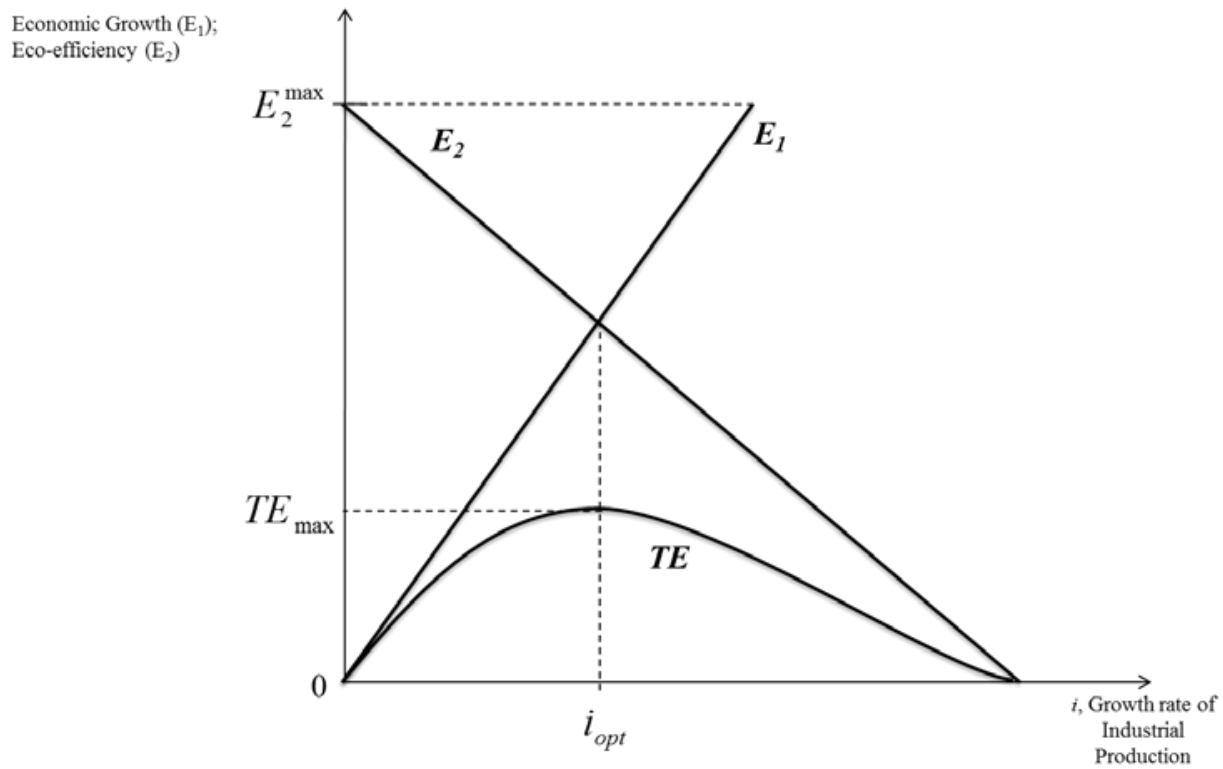

Fig. 1. Dependence of economic growth $\left(E_{1}\right)$ and ecological efficiency $\left(E_{2}\right)$ on growth rates of industrial production. The Source: Author.

The main idea of the Figure 1 is optimal industrial growth rate. Industrial production is prioritized while eco-efficiency $\left(E_{2}\right)$ exceeds economic efficiency. Further industrial development after reaching optimal level $\left(i_{\text {opt }}\right)$ will lead to further economic growth (higher GRP growth rate) with worsening eco-efficiency, beyond acceptable level. The intersection of the two so-called contradictory curves $\left(E_{l}\right.$ и $\left.E_{2}\right)$ is an optimal "eco-balance" point.

Supposing that economic growth $\left(E_{l}\right)$ as well as eco-efficiency $\left(E_{2}\right)$ have a certain level of elasticity relating to industrial production growth rate, graphically it will result in 
different slope of the curves. Technological upgrading, for example, accompanied by industrial production growth, will not result in significant decline of eco-efficiency. In this case the curve $E_{2}$ loses its elasticity, and becomes flatter (Figure 2). Thus, level of optimal industrial production growth rate will rise favoring economic growth.

Economic Growth $\left(E_{1}\right)$;
Eco-efficiency $\left(E_{2}\right)$

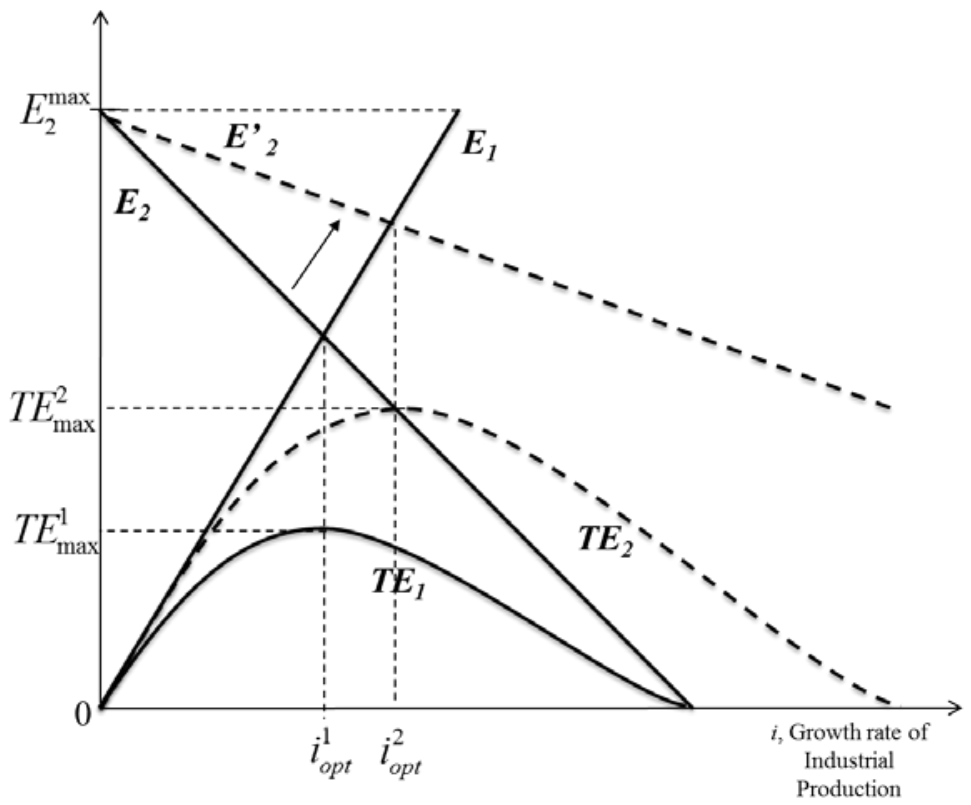

Fig. 2. Change of optimal industrial production growth rate $\left(i_{\text {opt }}\right)$ resulting from change of ecoefficiency elasticity $\left(\mathrm{E}_{2}\right)$. The Source: Author.

Author's concept correlates with the widespread idea of "threshold hypothesis". The latter describes economic effect of excessive development, when at a certain level system's growth stops to pay off [21]. In our case, rate of pollutant emissions to the atmosphere is a key indicator restricting excessive growth.

Methodology for estimating eco-economic efficiency is formed by the following tools:

1) Correlation analysis. The calculation of paired correlation factor is held involving

- nominal GRP growth rate $\left(E_{l}\right)$ and industrial production growth rate $(X)$ (Industrial production growth rate in Figure 1, and Figure 2 is marked as $i$. In further calculations and mathematical functions it is designated as $X$ );

- rate of eco-efficiency $\left(E_{2}\right)$ and industrial production growth rate $(X)$.

Territories involved in calculation are Kurgan region, Svedlovsk region, Tyumen region (Includes indicators of KMAR and YNAR), and Chelyabinsk region. Observation period : 1995 - 2018. Number of observations : 23.

2) Regression analysis. Paired regressions (3) and (4) are built for every region involved:

$$
E_{1}=k X+c
$$

where

$E_{1}$ - namely GRP growth rate of specific region,

$X$-industrial production growth rate,

$k, c$-parameters of the linear function. 


$$
E_{2}=a-b \cdot X
$$

where

$E_{1}$ - inverse value of pollutant emissions growth rate in specific region,

$X$ - industrial production growth rate,

$a, b$-parameters of the linear function.

3) Graphical modeling. At this stage functions, using data provided by regression analysis, are built. According to the model presented in Figure 1, functions $E_{1}$ and $E_{2}$ are built for every region.

4) Algebraic approach to search for optimal growth rate of industrial production in every region. In order to receive required values we equate (4) and (5):

$$
\begin{gathered}
E_{1}=E_{2} \\
k X+c=a-b \cdot X \\
k X+b \cdot X=a-c \\
(k+b) \cdot X=a-c \\
i_{\text {opt }}=\frac{a-c}{k+b}
\end{gathered}
$$

\section{Results}

The author conducted similar research regarding the entire Urals Federal District in previous work. The correlation coefficient between economic growth and industrial production growth rate amounted to 0.47 , while the value of paired correlation between pollutant emissions and growth rate of industrial production was even higher-0.6. The coefficient is positive if it's calculated in regard of pollutant emissions growth rate (growth of production inevitably causes growth of pollution). However, the value of paired correlation coefficient becomes negative if it's calculated in regard of eco-efficiency. It should be borne in mind that eco-efficiency coefficient is inversely proportional to pollution growth rate. Inverse indicator is introduced by the author in order to create graphical models.

Table 1 demonstrates the results of paired correlation for every region of the Urals.

Table 1. Results of correlation analysis (Source: calculations of the author based on data from Rosstat).

\begin{tabular}{|l|c|c|}
\hline \multirow{2}{*}{ Region } & \multicolumn{2}{|c|}{ Value of the correlation coefficient } \\
\cline { 2 - 3 } & between $E_{1}$ and $X$ & between $E_{2}$ and $X$ \\
\hline Kurgan & 0.01 & -0.01 \\
\hline Sverdlovsk & 0.68 & -0.49 \\
\hline Tyumen & 0.35 & -0.57 \\
\hline Chelyabinsk & 0.63 & -0.59 \\
\hline
\end{tabular}

It should be noted that only growth rates are used in the calculations, not absolute values. In that regard, let's assume that the correlation coefficient of 0.35 and higher signifies relatively strong connection between absolute values. According to the author, implementation of this method helps to avoid auto-correlation during econometric analysis.

The lowest values (near-zero) are demonstrated by Kurgan region, which leads to the conclusion that industrial production is neither driving force of economic growth, nor ecoefficiency factor for Kurgan region. In comparison with other regions, Kurgan is 
significantly less industrially developed, that's why such results do not surprise. Nevertheless, if we compare level of industrial production in economies of two regions, Sverdlovsk, and Kurgan, we can notice that in Sverdlovsk, historically one of the most industrially developed regions, this indicator is just slightly bigger than in Kurgan region (37.8\% vs. $30.4 \%)$, which merits attention. However, taking into account absence of direct connection, we eliminate Kurgan region from the sample, because its results do not allow us neither to build paired regressions nor to create graphic models.

The results of paired regressions, and graphic models of the functions are presented in Figures 3-5.
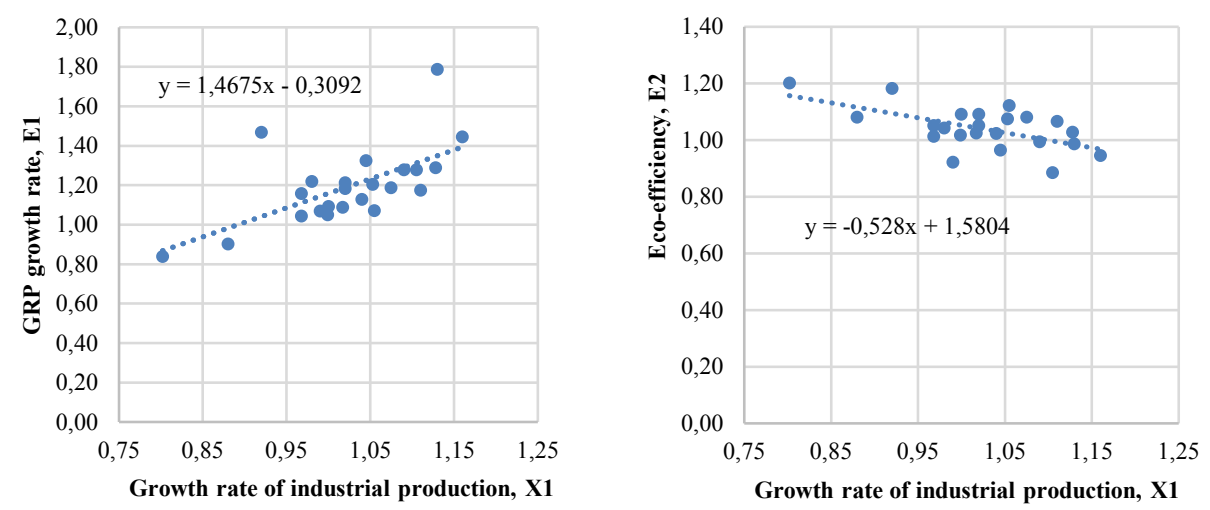

Fig. 3. Chelyabinsk region: graphic models of functions $E_{1}$ and $E_{2}$. Source: calculations made by the author.
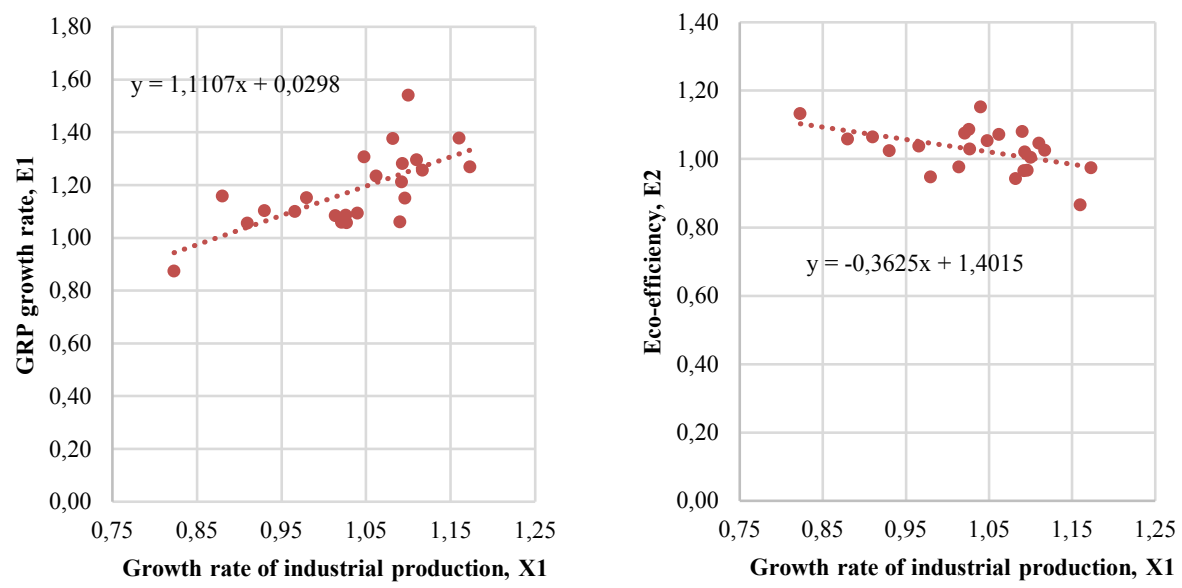

Fig. 4. Sverdlovsk region: graphic models of functions $E_{1}$ and $E_{2}$.Source: calculations made by the author. 

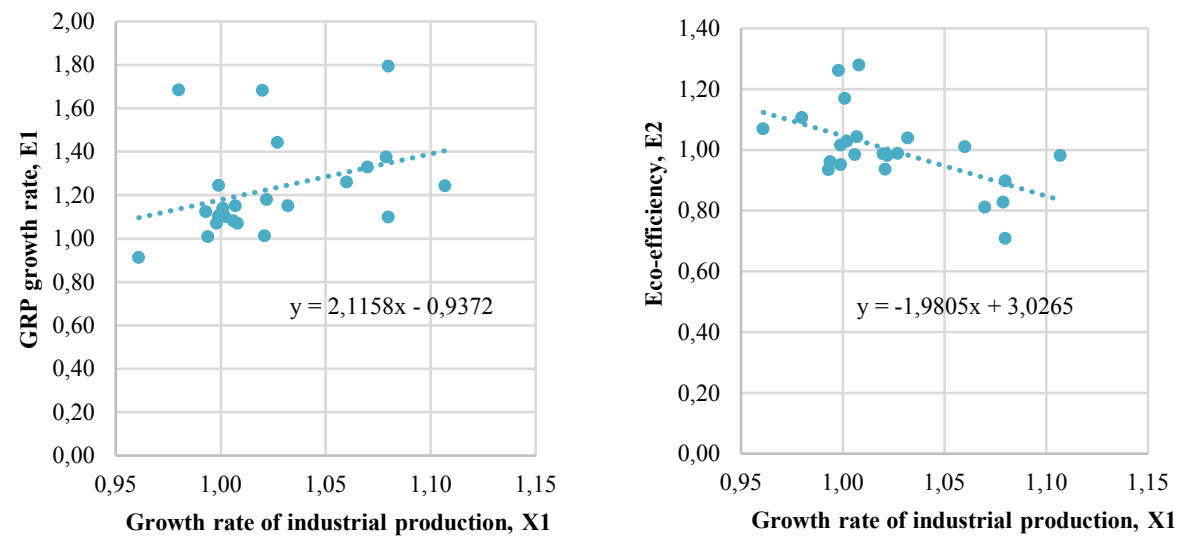

Fig. 5. Tyumen region: graphic models of functions $E_{1}$ and $E_{2}$. Source: calculations made by the author.

With the equations of paired regressions presented in the Figures 3-5 we can find optimal values of industrial development growth rate. Optimum for Chelyabinsk region is as follows:

$$
\begin{gathered}
E_{1}=E_{2} \\
1.4675 X-0.3092-1.5804-0.528 X \\
X_{\text {Chel }}=0.9469
\end{gathered}
$$

Optimal level of industrial production for Sverdlovsk region:

$$
\begin{aligned}
1.1107 X+0.0298 & =1.4015-0.3625 X \\
X_{\text {Sverdl }} & =0.9311
\end{aligned}
$$

Values for Tyumen region are:

$$
\begin{aligned}
2.1158 X-0.9372 & =3.0265-1.9805 X \\
X_{\text {Sverdl }} & =0.96763
\end{aligned}
$$

It should be noted that the values obtained differ only very slightly from each other, and all of them are less than 1. Numbers greater than 1 indicate that industrial production growth is accompanied by sufficient level of eco-efficiency. Current results reflect the necessity to decrease industrial production in every region $(3.24 \%$ in Tyumen region, $5.31 \%$ in Chelyabinsk region, and $6.89 \%$ in Sverdlovsk region) in order to sustain appropriate level of eco-efficiency. It may be concluded that decreased industrial production will inevitably lead to decline in GRP. But if we insert the values of $i_{\text {opt }}$ into the equations $E_{1}$ and $E_{2}$ we'll see that the situation is quite the opposite. Besides, with the value of $E_{2}$ we can calculate pollutant emissions growth rate building on formula (3). All the numerical values are presented in Table 2 . 
Table 2. Growth rate of economy and pollutant emissions growth rate in accordance with obtained optimal level of industrial production growth rate, $\%$.

\begin{tabular}{|c|c|c|c|}
\hline Region & $\begin{array}{c}\text { Value of optimal } \\
\text { industrial production } \\
\text { growth rate } \boldsymbol{i}_{\text {opt }}\end{array}$ & $\begin{array}{c}\text { GRP growth rate } \\
\left(\boldsymbol{E}_{\boldsymbol{1}}\right) \text { taking account } \\
\text { of obtained } \boldsymbol{i}_{\text {opt }}\end{array}$ & $\begin{array}{c}\text { Pollutant emissions } \\
\text { growth rate }\left(\mathbf{1 / \boldsymbol { E } _ { 2 } )}\right. \\
\text { taking account of } \\
\text { obtained } \boldsymbol{i}_{\text {opt }}\end{array}$ \\
\hline Sverdlovsk & 93.11 & 106.40 & 93.99 \\
\hline Tyumen & 96.76 & 111.01 & 90.08 \\
\hline Chelyabinsk & 94.69 & 108.04 & 92.25 \\
\hline
\end{tabular}

\section{Discussion and Conclusion}

Scientific community has spent many years searching for drivers of economic growth. Numerous studies have been undertaken including those with regard to mathematical modeling of economic growth, the foundation of which was laid by J. M. Keynes. Opposed to liberal approach, Keynes emphasized the efficiency of multipliers and investment as basic drivers of macroeconomic frameworks [11]. Neo-Keynesians E. Domar and R. Harrod also pointed out the key role of investment [6,9]. Models of economic growth in contemporary studies are commonly based on Solow and Cobb-Douglas models [4, 19]. The results of these studies do not deny the importance of fixed capital investment; however, employment prevails over investment in a number of models [2]. Significance of human capital is well-known in scientific community since R.Lucas, S.Rebelo, and P.Romer emphasized human factor within the models of economic growth [12, 14, and 15].

Issues of regional development are studied in the works of Russian scientists [7, 18]. In a number of works further growth of the Urals region is based on the idea of new industrialization [18] with technological modernization as the main driver of economic development. Current trends in the regions, however, demonstrate very different dynamics of GRP and fixed capital investment. It is necessary to find out if there is a way to reach a new technological framework for the Urals. Working on this issue we discovered that fixed capital investment has low elasticity regarding to economic growth both on regional level and within industrial markets [2]. With respect to short-term and long-term bank credits targeting fixed capital investment, none of them have proven successful. Thus, we have to face a new reality, when classic stimulators of economic growth no longer work [18]. Even modest economic growth is often provided by industrial production. A number of advanced economies have already legislated eco-management, while the very idea of ecoresponsibility remains quite unpopular among Russian industrial regions.

Economic development, achieved by increased consumption and industrial growth, cannot continuously remain the key issue for national strategies. By the end of the 20th century global community had to face the negative consequences of limitless economic growth, when environmental problems intensified. Greenhouse effect [1], inability to fill the resource gaps along with increasing electricity consumption $[3,13]$ became the most discussed issues. The First World Conference on Environment in 1972 resulted in the introduction of a new concept called "sustainable development". Within this concept economic growth must never be the sole objective without regard to environmental and social factors. Sustainable development has even become an essential part of people's mentality [20, 21]. Effectiveness of sustainable development does depend on how efficiently the new principles of consumption, garbage sorting and recycling enter into public consciousness.

Nowadays, more and more studies are conducted with regard to economic and environmental factors. Business community, along with social responsibility, puts into practice eco-responsibility $[8,10,16]$. Indicators of sustainable development become an 
essential part of business reports [10]. According to newly emerging concepts, business capitalization correlates with balance of economic, social, and ecological interests [16]. Development of modern cities is studied simultaneously within sustainable development and knowledge management concepts [17].

Such tendencies result in newly emerging categories, frequently occurring in foreign scientific literature, for instance, eco-efficiency, eco-sufficiency, energy efficiency, sustainable development, green economy, and so on [4, 8, 22]. And moreover a number of modern scientists have attempted to quantify eco-efficiency [22]. Chinese scientists, using newly implemented curves of resource efficiency, eco-efficiency, and biological efficiency of China, have analyzed trends of eco-efficiency over the period 1978 - 2016 [22].

Green economy has gone beyond theoretical framework and stopped being just a new term nowadays. The challenge scientific society faces is to embed green economy within the system of international economic relations with methodological, technological, and practical support. Economic researches, based on fundamental terms, practical implementation, and concept of green economy are frequently carried out on a piecemeal basis. Modern economic studies must be focused on a person, because social and economic development becomes possible on condition that a person (not economic human) adequately identifies himself with the modern world. Nowadays economic science obviously must use data provided by at least related sciences.

According to the findings of the study, industrial production growth rate in all regions investigated is less than 1, which in our case signifies the decline in industrial production. Table 2 (middle column), however, shows that economic growth is possible even in conditions of decreasing production. And moreover, according to the right column of Table 2 with all the values lower than $100 \%$, reduction of pollutant emissions is observed. Thus it can be concluded that decreasing industrial production does not prevent economic development of the Urals Federal District, while reduction of pollutant stationary source emissions is obviously beneficial to all.

The equations in Figures $3-5$ determine the level of industrial production providing zero growth of GRP. Equating $E_{l}$ (economic growth equation) $=1$, we obtain the following values of industrial production for each region: Chelyabinsk region $-89.21 \%$, Sverdlovsk region $-87.35 \%$, Tyumen region $-51.69 \%$. These numbers show that every region has a "reserve" in economic development. For instance, zero growth of GRP in Chelyabinsk, Sverdlovsk, and Tyumen regions will be observed in case industrial production in every region decreases by $10.79 \%, 12.65 \%$, and $48.31 \%$ respectively.

By the conclusion, it should be noted that current research is not aimed to support output contraction. Methods of constructing single-factor functions require other equal conditions, in view of the fact that in practice economic growth is determined not only by the factor of industrial production. Research of eco-efficiency does not take into account the whole range of industrial emissions, for instance, water pollution. Any econometric model has a certain level of significance implying only partial approximation of source data.

\section{References}

1. J. Ananda, B. Hampf, Ecological Economics 116, 211-219 (2015) DOI: https://doi.org/10.1016/j.ecolecon.2015.04.025

2. V. Barkhatov, D. Benz. Upravlenets -The Manager 10(3), 83-93 (2019) DOI: 10.29141/2218-5003-2019-10-3-8 
3. J. Brown, W. Burnside, A. Davidson, J. DeLong, W. Dunn, M. Hamilton, J. Nekola, J. Okie, N. Mercado-Silva, W. Woodruff, W. Zuo 61(1), 19-26 (2011) DOI: https://doi.org/10.1525/bio.2011.61.1.7

4. R. Caiado, R. Dias, L. Mattos, O. Quelhas, W. Filho, Journal of Cleaner Production 165, 890-904 (2017) DOI: https://doi.org/10.1016/j.jclepro.2017.07.166

5. C. Cobb, P. Douglas, A Theory of Production. American Economic Review 18(1), 139-165 (1928)

6. E. Domar, Expansion and Employment. The American Economic Review 37(1), 34-55 (1947)

7. E. Dvoryadkina, E. Kaibicheva, I. Antipin, Advances in Economics, Business and Management Research (AEBMR) 39, 543-546 (2019) DOI: https://doi.org/10.2991/cssdre-18.2018.112

8. P. Heikkurinen, W. Young, E. Morgan, Journal of Cleaner Production 218, 656-664 (2019) DOI: https://doi.org/10.1016/j.jclepro.2019.02.053

9. R. Harrod, Mr. Keynes and Traditional Theory. Econometrica 5, 74-86 (1937)

10. N. Kanie, R. Zondervan, M. Betsill, New Visions of Sustainable Development Governance (United Nation University, 2011) https://unu.edu/publications/articles/new-visions-of-sustainable-developmentgovernance.html

11. J. Keynes, The General Theory of Employment, Interest and Money (1936) http://www.hetwebsite.net/het/texts/keynes/gt/gtcont.htm

12. R. Lucas, Journal of Monetary Economics 22, 3-42 (1988) DOI: https://doi.org/10.1016/0304-3932(88)90168-7

13. Z. Mi, J. Zheng, J. Meng, Y. Shan, H. Zheng, J. Ou, D. Guan, Y. We, Earth's Future 6, 1007-1016 (2018) DOI: https://doi.org/10.1029/2018EF00084

14. S. Rebelo, The Journal of Political Economy 99(3), 500-521 (1991) DOI: $10.1086 / 261764$

15. P. Romer, The Journal of Political Economy 94(5), 1002-1037 (1986) DOI: $10.1086 / 261420$

16. J. Sachs, The Age of Sustainable Development (2015)

17. Shahraki, Frontiers of Architectural Research 8(4), 471-482 (2019) DOI: https://doi.org/10.1016/j.foar.2019.04.004

18. Ya. Silin, E. Animitsa, N. Novikova, Ekonomika regiona - Economy of the region 12(3), 714-725 (2016) DOI: 10.17059/2016-3-9

19. Solow, The Quarterly Journal of Economics 70(1), 65-94 (1956) DOI: https://doi.org/10.2307/1884513

20. M. Weinstein, E. Turner, C. Ibáñez, Sustainability: Science, Practice, \& Policy 9, 4-15 (2013)

21. M. Weinstein, S. Litvin, J. Krebs, Ecological Engineering 65, 71-87 (2014) DOI: 10.1016/j.ecoleng.2013.03.001

22. L. Yang, Y. Yang, Science of The Total Environment 662, 581-590 (2019) DOI: https://doi.org/10.1016/j.scitotenv.2019.01.225 